DOI: 10.20472/IAC.2018.036.027

\author{
ELENA LVINA \\ Saint Joseph's University Haub School of Business, United States \\ C. KEN WEIDNER II \\ Saint Joseph's University Haub School of Business, United States
}

\title{
PROBLEM-BASED LEARNING AND EVIDENCE BASED MANAGEMENT IN “EXECUTIVE GRAND ROUNDS”
}

\begin{abstract}
:
In this study, we discuss a pedagogical innovation we've termed "Executive Grand Rounds" and demonstrate its merits for graduate students. Executive Grand Rounds is a teaching method that combines case-based experiential learning and the traditional "grand rounds" method historically used in medicine. Despite its evident benefits in medical education (e.g., Van Hoof, Monson, Majdalany, Giannotti, \& Meehan, 2009), the grand rounds method has not been reported as being applied to teaching MBA students. In this paper, we demonstrate how self-generated case analysis can be integrated into grand rounds and explain how our approach can successfully build on the principles of Project based learning (PBL) and Evidence based management (EMB). We also discuss how Executive Grand Rounds can mitigate some frequently reported challenges of PBL and EBM. Upon describing the use of the method in the Leading Teams course taught within a cohort-based Executive Master of Business Administration (EMBA) program, we provide empirical evidence that EGR results in a highly engaged class of self-directed learners effectively applying research to everyday situations to (a) build successful teams, (b) engage in critical thinking based upon a body of knowledge, and (c) to develop their own leadership capacity. In our experience, Executive Grand Rounds - particularly when student cases are analyzed in and by a team - lead to multiple perspective and solutions, encouraging diversity of thinking and critical thinking skills. Based on EMBA students' achievement of learning outcomes, qualitative and quantitative feedback from students, and our own assessment of executive grand rounds, we are encouraged by the results and invite the larger teaching community to further adapt and refine this distinctive pedagogical process.
\end{abstract}

\section{Keywords:}

Executive education, Project-Based Learning, Evidence Based Management 